\title{
A novel method of endoscopic-assisted esophageal clearance in advanced achalasia $\square$
}

\section{(ㄷ)(이우}

Authors

Shinwa Tanaka ${ }^{1}$, Fumiaki Kawara ${ }^{1}$, Takashi Toyonaga ${ }^{2}$, Robert Bechara ${ }^{3}$, Namiko Hoshi ${ }^{1}$, Hirofumi Abe ${ }^{1}$, Yoshiko Ohara', Tsukasa Ishida', Yoshinori Morita'1, Eiji Umegaki ${ }^{1}$

Institutions

1 Division of Gastroenterology, Department of Internal Medicine, Graduate School of Medicine, Kobe University, Kobe, Japan

2 Department of Endoscopy, Kobe University Hospital, Kobe, Japan

3 Gastrointestinal Diseases Research Unit, Queens University, Ontario, Canada

submitted 21.5.2017

accepted after revision 26.9.2017

\author{
Bibliography \\ DOI https://doi.org/10.1055/s-0043-122229 | \\ Endoscopy International Open 2018; 06: E86-E89 \\ (c) Georg Thieme Verlag KG Stuttgart · New York \\ ISSN 2364-3722
}

Corresponding author

Shinwa Tanaka, Division of Gastroenterology, Department of Internal Medicine, Graduate School of Medicine, Kobe University, 7-5-1 Chuo-ku, Kusunoki-cho, Kobe, Hyogo

650-0017, Japan

Fax: +81-78-382-6309

tanakas@med.kobe-u.ac.jp

\section{ABSTRACT}

Background and study aims In order to perform peroral endoscopic myotomy (POEM) safely, retained liquid and food debris must be removed before the procedure is started. We developed a novel technique using a super-slim gastroscope, and a gastric tube to remove retained food debris in achalasia patients. In this study, the safety and efficacy of this novel technique were investigated

Patients and methods Eleven patients with achalasia were enrolled in this study and underwent this novel method for esophageal clearance.

Results All patients had complete clearance of the retained food debris using this method. The median procedure time (range) was $13(6-30)$ minutes. There were no serious adverse events (AEs) and one minor AE of mucosal erythema due to mucosal suctioning.

Conclusion This novel method for esophageal clearance is safe and effective in achalasia patients with large amounts of retained food debris.

\section{Introduction}

Recently, an innovative endoscopic technique, peroral endoscopic myotomy (POEM), has been developed to treat achalasia and has demonstrated excellent clinical outcomes [1 -4]. In order to perform POEM safely, retained food and fluids must be cleared prior to the start of the POEM procedure. In advanced achalasia where the esophagus is severely dilated and angulated, there is often a large amount of retained food requiring significant time and effort for removal. If the retained food debris cannot be removed endoscopically, then the patient must undergo a prolonged fasting period to allow for esophageal clearance. Thus, a more efficient and effective method for esophageal clearance is necessary for these patients. We developed a novel technique using a super-slim gastroscope and a gastric tube to definitively clear food debris in achalasia pa- tients. In this study, the safety and efficacy of this novel technique was investigated.

\section{Patients and methods}

\section{Patients}

This study was conducted at the endoscopy unit at Kobe University Hospital in Japan. Informed written consent was obtained from all patients prior to enrollment. The study was approved by the Ethics Committee of Kobe University Hospital (No. 160060). Procedural data were prospectively collected. Consecutive achalasia patients who underwent POEM from April to November 2016 were recruited for this study. Patients were eligible if during the endoscopic examination performed the day prior to POEM, a large amount of retained food debris was present that could not be suctioned via a standard endo- 

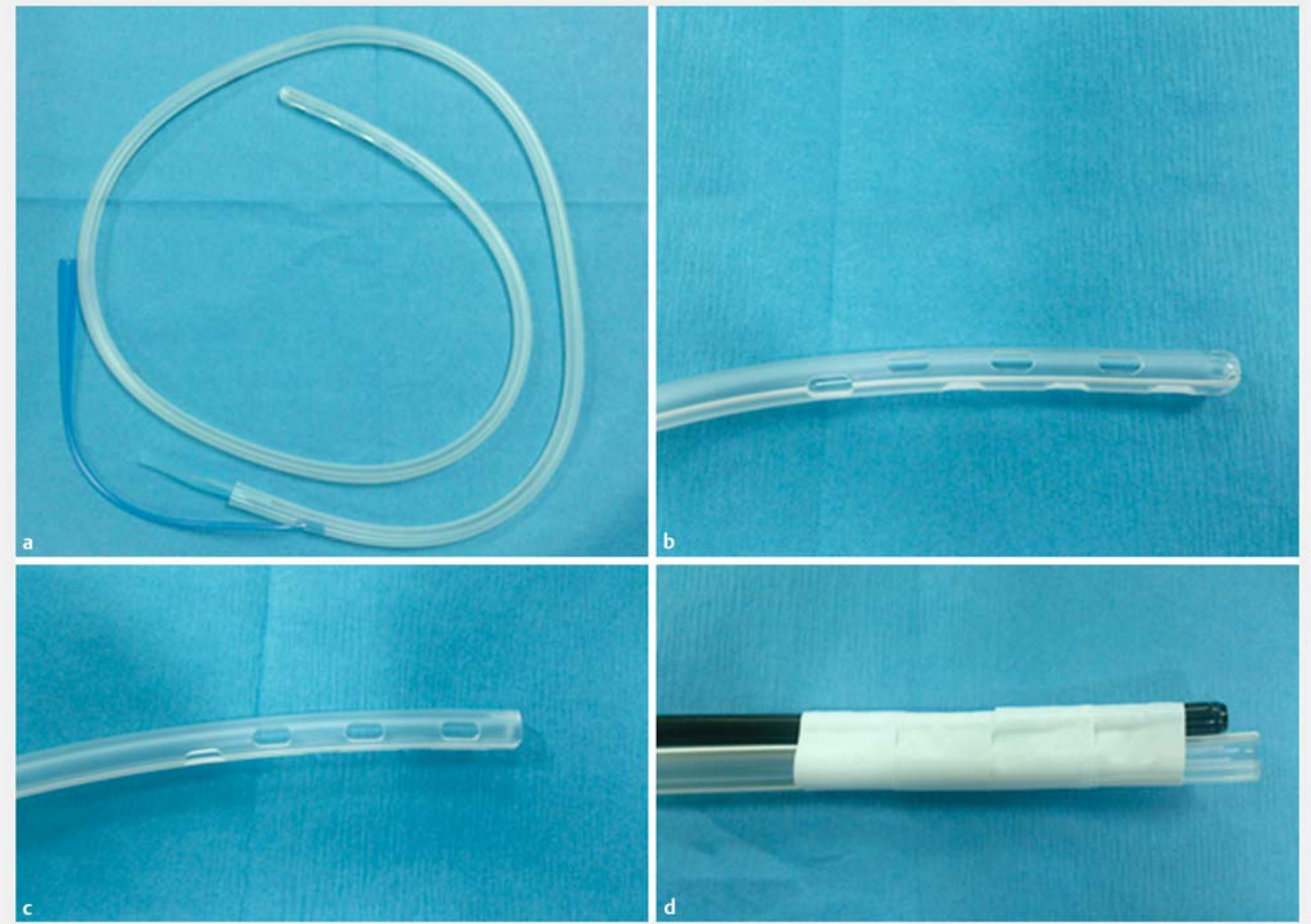

- Fig. 1 a, b 26Fr gastric tube. c The gastric tube was cut away at the tip. $\mathbf{d}$ The super-slim gastroscope and gastric tube were placed together with tape.

scope (GIF-260 J, Olympus Medical Systems, Tokyo, Japan). Enrolled patients were admitted 2 days prior to POEM and consumed only fluids for 24 hours. The following day ( 1 day prior to POEM), the removal of food debris was performed under conscious sedation with intravenous midazolam $(2.5-5 \mathrm{mg})$. The degree of esophageal dilatation was classified as grade I $(<3.5 \mathrm{~cm})$, grade II $(3.5$ to $6 \mathrm{~cm})$, or grade III $(>6 \mathrm{~cm})$ according to the diameter of the esophageal lumen on barium esophagram [5]. The type of esophageal lumen was also classified as sigmoid or non-sigmoid based on the barium esophagram. Sigmoid-type achalasia was defined as a significantly dilated and tortuous esophagus on barium esophagram. Sigmoid-type achalasia was sub-classified into sigmoid type 1 (S1) or sigmoid type 2 (S2) based on CT findings; presence of a double lumen on axial CT slices was defined as S2 sigmoid, while if only a single lumen was present, that defined S1 sigmoid [2].

\section{Esophageal clearance technique}

First, the overtube (16675; Top Corporation, Tokyo, Japan) was placed using a standard gastroscope (GIF-Q260), Olympus Medical Systems, Tokyo, Japan). Second, a 26Fr gastric tube (226ES, Covidien Ltd, Dublin, Ireland) with a cut tip was taped to the super-slim $5.8 \mathrm{~mm}$ gastroscope (GIF-XP290N, Olympus Medical Systems, Tokyo, Japan) ( $\triangleright$ Fig. 1). The gastric tube was positioned to allow direct endoscopic visualization of the distal end of the gastric tube. The tape was used to fasten the gastric tube to the super-slim gastroscope ensuring occlusion the side holes of the gastric tube to confirm that suction is only applied in the area endoscopically visible and to prevent mucosal damage from inadvertent non-targeted suctioning. The super-slim gastroscope with the attached gastric tube was then inserted into the esophagus through the overtube. When the endoscope reached the food debris, the gastric tube was connected to suction and the food debris suctioned under direct visualization ( $\triangleright$ Fig.2). The success rate of esophageal clearance, procedure time and adverse events were recorded. Procedure time was measured from the insertion of the standard gastroscope until food the debris was completely cleared $>$ Video 1 . 

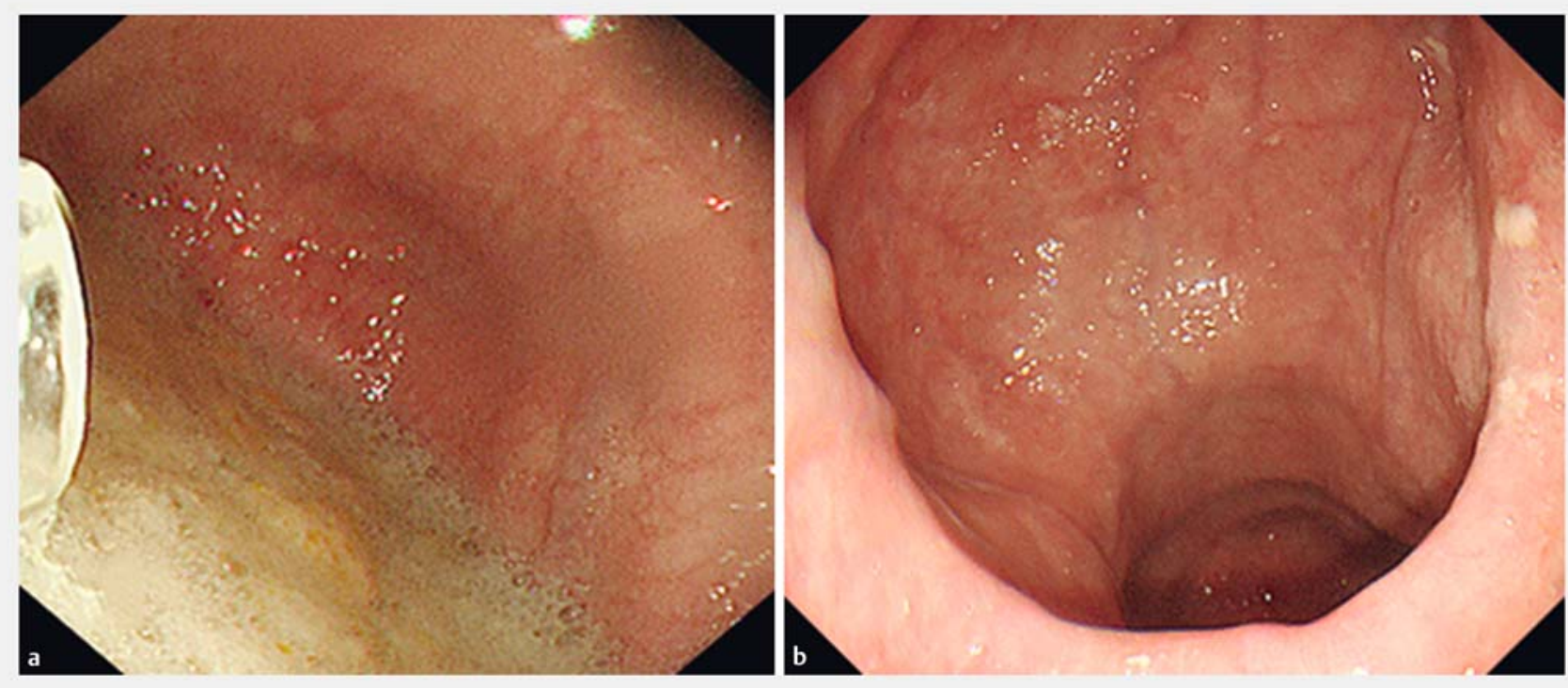

Fig. 2 a Before suction. b After suction.

\section{Results}

\section{Patient characteristics}

Fifty-six patients underwent POEM from April to November 2016. Of them, 11 patients with achalasia were enrolled in this study and underwent this novel method of esophageal clearance. Patient characteristics are shown in $>$ Table 1. Median age of the patients (range) was $47(27-76)$ years, and the study population consisted of 6 male and 5 female patients. Median duration of achalasia symptoms (range) was 12 (0.230) years. The median body mass index (range) was 21.3 $(15.6-32.7) \mathrm{kg} / \mathrm{m}^{2}$. The degree of esophageal dilatation was grade I in one patient (9.1\%) and grade II in 10 patients $(90.1 \%)$. The type of achalasia was non-sigmoid in 5 patients

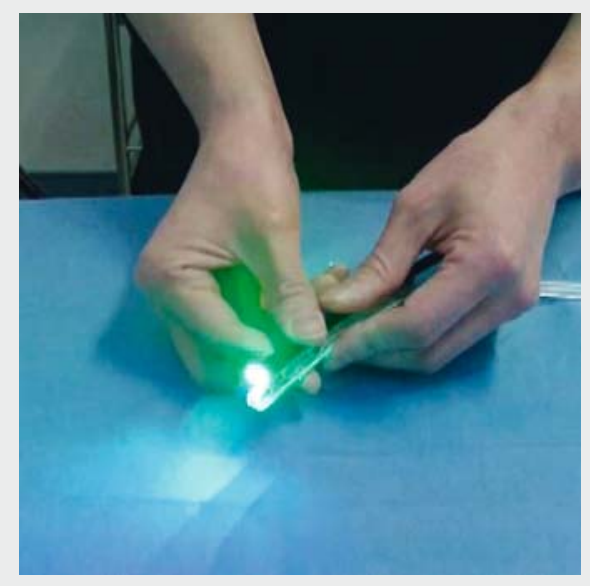

Video 1 Esophageal clearance technique.
- Table 1 Patient characteristics.

\begin{tabular}{|c|c|}
\hline & $n=11$ \\
\hline Age, years, median [range] & $47[27-76]$ \\
\hline \multicolumn{2}{|l|}{ Sex } \\
\hline - Men & 6 \\
\hline - Women & 5 \\
\hline BMI, kg/m2 [range] & $21.3[15.6-32.7]$ \\
\hline Duration of symptoms, years, median [range] & $12[0.2-30]$ \\
\hline \multicolumn{2}{|l|}{ Degree of dilatation } \\
\hline - Grade I & 1 \\
\hline - Gradell & 10 \\
\hline \multicolumn{2}{|l|}{ Type of achalasia } \\
\hline - Non-sigmoid type & 5 \\
\hline \multicolumn{2}{|l|}{ - Sigmoid type } \\
\hline - Type 1 & 2 \\
\hline - Type 2 & 4 \\
\hline \multicolumn{2}{|l|}{ Chicago classification, n } \\
\hline - Type I & 6 \\
\hline - Unknown & 5 \\
\hline Eckardt score, median [range] & $4[2-7]$ \\
\hline IRP, mmHg, median [range] & $28.5[22.8-57.3]$ \\
\hline \multicolumn{2}{|l|}{ Primary procedure, n (\%) } \\
\hline Balloon dilatation & 4 \\
\hline BMI, body mass index & \\
\hline
\end{tabular}


- Table 2 Procedure-related parameters.

Median procedure time, minutes (range)

$13(6-30)$

Adverse events, $\mathrm{n}(\%)$

- Mucosal redness

(45.5\%), S1 sigmoid in 2 patients (18.2\%) and S2 sigmoid in 4 patients (36.4\%). Moreover, manometry examinations could not be completed in 5 patients (45.6\%) due to the degree of resistance at the LES or to esophageal tortuosity.

According to the Chicago classification v3.0, manometric findings were classified as type I in 6 patients and in 5 patients, manometry was not completed because of difficulty in inserting the catheter through the LES [6]. The median integrated relaxation pressure (range) was $28.5(22.8-57.3) \mathrm{mmHg}$. The median Eckardt score (range) was $4(2-7)$. Four patients had undergone balloon dilation prior to inclusion in this study.

\section{Procedure-related outcomes}

- Table 2 shows procedure-related outcomes. All patients had successful esophageal clearance using this novel method. Median procedure time (range) was $13(6-30)$ minutes. In terms of adverse events (AEs), mucosal erythema due to mucosal suctioning occurred in 1 patient. There were no severe AEs such as bleeding or perforation.

\section{Discussion}

Retained food debris must be cleared prior to POEM to minimize the risk of postoperative infection or aspiration during endotracheal intubation. Generally, in achalasia patients with a significantly dilated, tortuous and angulated esophagus, a large amount debris is often retained. To achieve effective esophageal clearance of food debris, a large caliber channel is necessary. The size of the working channel of an upper endoscope is $3.2 \mathrm{~mm}$ (GIF-Q260), Olympus Medical Systems, Tokyo, Japan) and that of even a colonoscope or therapeutic gastroscope endoscope is $3.7 \mathrm{~mm}$ (CF-HQ290L/I or GIF-2401T, respectively, Olympus Medical Systems, Tokyo, Japan). In contrast, the caliber of the gastric tube is $6.5 \mathrm{~mm}$, which is much larger than that of any gastroscope or colonoscope. In addition, the $16 \mathrm{~mm}$ overtube also offers a degree of airway protection. Using this combination of equipment, endoscopic maneuverability is smooth within the esophagus and large amounts of food debris can be safely and easily cleared. If there are large solid pieces of food that are not amenable to suctioning even with the large caliber gastric tube, they can be cut with a snare prior to being suctioned or even extracted safety from the patient due to the overtube in place protecting the airway.
Median procedure time (range) was $13(6-30)$ minutes, which was relatively short indicating relatively smooth and efficient procedures. There are 2 key reasons for the efficiency and effectiveness of this technique. Firstly, suctioning food particles with the gastric tube took place under direct visualizing via super-slim gastroscope. Secondly, in many patients with large volumes of retained food, there was a spontaneous flow of material out through the overtube upon insertion due to the pressure gradient between the esophagus and the outside environment.

In terms of AEs, no major AEs occurred and only 1 minor case of mucosal erythema due to suctioning occurred. Serious AEs such as bleeding and perforation did not occur. However, vigorous non-targeted suctioning may pose a risk of bleeding and perforation. To prevent such events, the gastric tube must be connected to a vacuum aspirator only after the super-slim gastroscope reaches to and is targeted at the retained food material. In addition, intermittent disruption of the suction may be necessary to allow the operator to reorient themselves if visibility is lost.

Although this clearance procedure was performed one day before POEM in this study, it can also be performed immediately before POEM under general anesthesia. That strategy can make hospital stay shorter and may be a more efficient approach. conclusion, this novel method of esophageal clearance is safe and effective in patients with achalasia that have large amounts of retained food debris in the esophagus where conventional endoscopic clearance may be difficult or even impossible.

\section{Competing interests}

\section{None}

\section{References}

[1] Inoue H, Minami H, Kobayashi Y et al. Peroral endoscopic myotomy (POEM) for esophageal achalasia. Endoscopy 2010; 42: 265-271

[2] Inoue $\mathrm{H}$, Sato $\mathrm{H}$, Ikeda $\mathrm{H}$ et al. Per-Oral Endoscopic Myotomy: A Series of 500 Patients. J Am Coll Surg 2015; 221: 256 -64

[3] Stavropoulos SN, Modayil RJ, Friedel D et al. The International Per Oral Endoscopic Myotomy Survey (IPOEMS): a snapshot of the global POEM experience. Surg Endosc 2013; 27: 3322 - 3338

[4] Von Renteln D, Fuchs KH, Fockens P et al. Peroral endoscopic myotomy for the treatment of achalasia: an international prospective multicenter study. Gastroenterology 2013; 145: 309-311

[5] Diseases JSoE. Descriptive Rules for Achalasia of the Esophagus. 4th ed. Tokyo: Kanehara Syuppan; 2012

[6] Kahrilas PJ, Bredenoord A], Fox M et al. The Chicago Classification of esophageal motility disorders, v3.0. Neurogastroenterol Motil 2015; 2: $160-174$ 